\title{
What can we learn about "engineering thinking in extreme situations" from the testimony by the Fukushima Dai Ichi plant manager?
}

\author{
A. Afrouss ${ }^{1}$, A. Portelli ${ }^{1 \& 2}$, F. Guarnieri ${ }^{1}$ \\ ${ }^{1}$ CRC-MINES ParisTech, Sophia Antipolis, France \\ ${ }^{2}$ ESAIP, Grasse, France
}

ABSTRACT: The concept of engineering thinking in emergency situations addresses an epistemological gap in the field of safety sciences, following the accident at Fukushima Dai Ichi. Institutional bodies have not grasped the need to study the conditions in which the plant's teams had to work to maintain the integrity of the facilities. However, an understanding of the situation as it unfolded is crucial to understanding the decisions taken by the actors during the crisis. It is clear that the description of the accident and its representation, as it is presented in reports prepared by various official agencies fails in this respect. The testimony of Masao Yoshida, director of the plant, helps to fill in some gaps. Transcripts of his testimony provide detailed information that is key to understanding the sequence of events triggered by the earthquake and tsunami of 11 March, 2011. This article shows the importance of the study of his testimony and highlights the relationship between the management of the nuclear accident and the concept of engineering thinking in emergency situations.

\section{INTRODUCTION}

The nuclear accident at Fukushima Dai Ichi is considered to be one of the most important in history, together with those at Three Mile Island and Chernobyl. However, institutional investigations of the accident do not capture the complexity of the situation that the plant's operators faced. To remedy this, the concept of engineering thinking in emergency situations had been developed (Guarnieri and Travadel, 2014); the concept will be defined later.

Following the accident, the plant's director Masao Yoshida testified to the Japanese government's Investigation Committee. The transcript of the hearing was released to the public. The hearings of 22 and 29 July 2011, has been available in French since March 2015 (Guarnieri et al., 2015). The following hearings will form volumes 2 and 3. The fourth volume will be devoted to the analysis of the corpus.

The director's testimony not only allows us to fill in the gaps in institutional reports, but also to gain a better understanding of the factors influencing decision-making and action in extreme situations.

This article demonstrates the value of Yoshida's testimony in thinking about engineering thinking in emergency situations. The first section analyses how the Fukushima Dai Ichi accident was presented in the principal investigation reports. The second section highlights the similarities between Yoshida's testimony and the narrative form of the story. Finally, the third section is a detailed examination of his testimony, and shows the usefulness of the contribu- tion to the development of engineering in extreme situations.

\section{ACCIDENT INVESTIGATION REPORTS}

This first section outlines the four institutional reports selected for this study, and the organizations that prepared them. The content of these reports is briefly summarized and analysed in terms of their representation of the accident.

\subsection{Institutional reports}

After the Fukushima accident, many institutions analysed the causes of the accident in order to draw out the main lessons and improve the safety of nuclear installations. Here we examine the reports of: the Investigation Committee on the Accident at the Fukushima Nuclear Power Stations, appointed by the Japanese government (ICANPS, 2012); the Independent Investigation Commission of the Japanese Diet (NAIIC, 2012); the Nuclear Energy Agency (NEA, 2013); and the United States National Academy of Sciences (NAS, 2014). These documents come from four agencies: two are Japanese, one is international and one is American, and they have different goals, draw different conclusions and propose different recommendations.

The Investigation Committee on the Accident at the Fukushima Nuclear Power Stations (ICANPS) was created following a decision of the Japanese government on 24 May, 2011. Yotaro Hatamura, 
Professor Emeritus of the University of Tokyo, chaired the ten-member committee. The other members were researchers and judges, assisted by eight technical and policy experts. The purpose of the Committee was to make recommendations to prevent the spread of the damage caused by the accident and the recurrence of similar accidents. Therefore, the investigation sought to identify the causes of the accident and the damage that it created. Its members were given the responsibility of conducting a thorough investigation that would produce satisfactory answers to all questions related to the accident, which would be valid for at least a century. The Committee undertook tours of the nuclear power plants at Fukushima Dai Ichi and Dai Ni, held hearings with the directors of local government authorities and others involved in the management of the accident. An interim report was published on 26 December 2011. The final report was presented to the Prime Minister on 23 July, 2012. The Committee was dissolved by order of the Prime Minister's Office on 28 September, 2012.

The Nuclear Accident Independent Investigation Commission (NAIIC) was set up by the Japanese Diet, under Article 10 of the law enacted on 30 October, 2011. On 8 December, 2011, the ten members of the Commission were appointed by the President of the Diet. It was headed by Kiyoshi Kurokawa, a doctor and former president of the Scientific Council of Japan. The Commission's nine other members consisted of scientists, lawyers and political actors. The NAIIC investigation analysed the causes of the accident and the damage it produced. It also looked at the reaction of stakeholders and the effectiveness of their management of the emergency. Finally, it proposed measures that could be applied in order to prevent another nuclear accident in Japan or limit its consequences. Both chambers of the Japanese Parliament insisted on the need to conduct this expert investigation, from both a theoretical and scientific viewpoint. It was tasked with producing recommendations to strengthen the legislative framework in Japan and benefit the nation in the future. Moreover, their recommendations were required to be formulated so that the whole world might benefit, and would therefore help to prevent another nuclear accident. Members of the Committee visited the five plants affected by the tsunami and interviewed more than a thousand people. Public meetings were held with residents who had been evacuated and workers at the plant. The results of the investigation were made public in a report published in September 2012.
One of the missions of the Nuclear Energy Agency (NEA) is to strengthen the legislative, scientific and technological foundations of nuclear safety within the Organisation for Economic Cooperation and Development (OECD). The report prepared by the Committee on Regulatory Nuclear Activities (CRNA), the Committee on the Safety of Nuclear Installations (CSNI) and the Committee on Radiation Protection and Public Health (CRPPH) was published in September 2013. Written under the leadership of Director General Luis Echávarri, this document enumerates the efforts of OECD member states to improve the management of safety in the wake of the accident, and offers some recommendations based on the key lessons learned. The report expresses the desire of the NEA to regularly to revise nuclear safety standards and to circulate the lessons learned to its members.

The United States National Academy of Sciences (NAS) finally published a report commissioned by the United States Nuclear Regulatory Commission in July 2014. The study was conducted by a committee of scientists and engineers with various skills. The committee, composed of twenty-one experts, was placed under the direction of Dr Norman P. Neureiter. Thirty-nine meetings were held in order to collect and exchange information. Visits to Japanese plants - including Fukushima Dai Ichi - and American plants with the same design took place. The purpose of the report was to summarize the various causes of the nuclear accident at Fukushima Dai Ichi, with a particular focus on the response of the operator. It also proposed recommendations to improve the safety of United States' nuclear facilities, from an operational and regulatory point of view.

\subsection{The representation of the accident in official reports}

An examination of the recommendations put forward in these reports shows the vulnerabilities that were identified by investigators and helps us to understand their representation of the accident. In this article, the concept of the representation refers to the mental map of subjects, related to the causal, proximal and influential relations "that an individual (or by extension a group of individuals) sees as a problem or a problematic issue" (Chaxel et al., 2014).

According to these four reports, the accident at Fukushima Dai Ichi highlights a lack of preparation on the part of the operator (TEPCO), and Japanese institutions in dealing with such an event. They state that TEPCO staff lacked adequate training and appropriate skills to respond to emergencies, and go on 
to say that communication between workers and decision-makers, as well as poor coordination between the various emergency response centres made it difficult to react effectively to the accident.

They also suggest that the accident was due to a failure to take into account global, state-of-the-art advances and new safety approaches, notably the defence-in-depth concept. They claim that TEPCO and Japanese institutions had not taken the steps necessary to bring the safety of their facilities up to international standards. Consequently, they emphasize the need to strengthen defence-in-depth measures and examine the possibility of beyond design-basis accidents or simultaneous accidents at multiple sites.

Another recommendation concerns the independence of the Japanese Nuclear and Industrial Safety Agency (NISA). Although this agency knew about TEPCO's safety weaknesses, it did not seek to rectify the situation. The skills, commitment and transparency of NISA were thus called into question, and the reform of the monitoring and regulatory system for Japanese nuclear facilities was identified as another key point to be addressed.

These accident analyses offer no innovative insights in nuclear safety. They focus on the need to strengthen the application of known concepts and to set higher safety margins to prevent further accidents. They advocate new standards and encourage the inclusion of overwhelming, multiple accidents. For the bodies concerned, the transparency and independence of the nuclear regulator, and the promotion of safety culture by the operator, are fundamental to ensuring safety at installations. The management of a major accident is therefore only represented in terms of the existing organisation and resources.

However, in such an accident, operators are faced with a scenario that goes far beyond anything previously considered. The lack of electricity and the worsening of the situation at Fukushima highlight the need to adapt to new and unforeseen conditions. Furthermore, the earthquake and tsunami damaged the country's infrastructure, hampering the delivery of both human and material resources to the plant.

To better understand what has to be done in such conditions, the concept of engineering thinking in emergency situations has been defined as "engineering activities that are significantly impeded due to a lack of resources in the face of a societal emergency" (Guarnieri and Travadel, 2014). Engineering thinking in emergency situations denotes engineering activities that are hampered by emergency conditions. Engineering takes places in a state of pronounced uncertainty, where this is a lack of human and material resources and high societal expectations.

Engineers must therefore adapt to the context and seek innovative solutions in order to overcome the lack of appropriate and available resources. Here, the organization corresponds to "a structure that results from a decision and takes the minimal form of a hierarchy, rules, a group ('members'), and supervisory and sanction instruments that are applicable to a specific activity with a particular goal" (Guarnieri et Travadel, 2014).

In contrast to the official reports, Yoshida's testimony provides another perspective on the accident. It clarifies points that were not fully addressed and demonstrates engineering thinking in emergency situations in action at Fukushima Dai Ichi in the aftermath of the earthquake and tsunami. In his account, the director explains his decisions and the actions that were carried out in an attempt to maintain the integrity of the reactors and limit damage to the facilities. He also reminds us of the difficult conditions in which these actions had to be undertaken.

\section{MASAO YOSHIDA'S TESTIMONY}

This section looks at the hearings where Masao Yoshida gave his testimony and highlights the similarities with the narrative story form. His account is then compared with the content of institutional reports, by highlighting parallels between this information and the concept of engineering thinking in emergency situations.

\subsection{Yoshida's testimony: a story of an accident}

The hearings that Masao Yoshida took part in were conducted by the ICANPS. The Committee interviewed several political and technical actors who participated in the management of the accident and its consequences. The director was convened to appear five times between 22 July and 6 November, 2011. These interviews lasted twenty-eight hours in total and primarily addressed the actions that were carried out in response to the accident. The transcript of the hearing was made public by the Japanese government on 11 September 2014 in the form of eleven documents.

Their content can be seen as a narrative of the nuclear accident. A narrative is an oral, written, drawn or ritualized representation of real or fictional events, arranged in chronological order and forming a coherent whole (Adam, 1996). A life history is defined as "a generic expression where one person 
tells their life or a part of their life to one or more interlocutors. This narrative may lead to a book, a recording or a film" (Legrand, cited in Burrick 2010).

In this case, the transcripts of the first two hearings correspond to a life history as they describe the fragment of Yoshida's life that unfolded at the Fukushima plant. His professional relations provide a better understanding of the organization that was in place at the time of the nuclear accident.

However, the two transcripts omit certain dimensions - notably, family and economic - found in the life stories usually studied by sociologists. The director did not have complete freedom to narrate his experience, as the format of the hearings followed a set of questions prepared by the investigators. Notwithstanding such 'limitations', there is still value for researchers in the question and answer format.

In practice, this testimony is the product of a 'semi-structured' interview, i.e. "a form of interaction similar to that of the conversation, through the ongoing adaptation of the researcher's questions and interventions as the exchange develops" (Nossik, 2011). In this story form, the interviewee (here Yoshida), orient their responses according to their understanding of the expectations of the questioner(s) (Brun, 2003). The interview is therefore an intersubjective construction created by its participants, who are in constant dialogue with the cultural, social and political context in which it takes place (Van Boeschoten, 2012). This form of interview also facilitates digression and provides opportunities for the narrator to relate anecdotes (Bernard, 2014).

The story form allows the researcher to identify the thoughts and feelings of the narrator, who reconstructs the story as they remember it. Here, it makes it possible to examine Yoshida's relationship with the story, the protagonists, and his interlocutors, i.e. the ICANPS investigators.

Deviations from the main thread of the story serve to make sense of the story, through recourse to explanations or comparisons. Additional details or information are provided to justify how the story unfolds and explain how events relate to each other: they serve to guarantee coherence and intelligibility. Yoshida therefore selects the events that he believes are significant and establishes "the connections that are necessary to make it coherent" (Bourdieu, 1986).

Yoshida's testimony is based on his personal memories. Facts are therefore reconstructed according to a - necessarily subjective - point of view. Although the main lines of the story are dictated by the investigator's questions, its overall meaning comes to life through the eyes of the person who is providing the testimony. This person uses their own representational system to establish consistency between the statements they make; therefore the story told at the hearing was necessarily "artificial, variable and partial" (Van Boeschoten, 2012).

These subjective biases only add value to personal testimony. Not only do these accounts contribute hitherto unpublished information to the recorded history of the event, they also make it possible to measure the orientation and the weight assigned to the event by the person giving the testimony (Ibid.).

The director chooses some striking metaphors: the damaged reactor is compared to "a living being that struggled in every way possible" (Guarnieri et al., 2015); or, realizing that forty of his staff might have died in the field, "I had decided to commit hara-kiri" (Ibid.). These statements demonstrate particularly clearly the huge difficulty and complexities that had to be taken into account in any decisions made in such an uncertain situation. His divergences from the main thread are particularly interesting, as they help in understanding the 'gaps' in official reports, where anything related to the emotions of the plant's director or its workforce was likely to be considered irrelevant. However, this information has a determining role in decision making, especially in extreme situations (Travadel and Guarnieri, 2015).

\subsection{Yoshida's account}

The study of Yoshida's narrative reveals connections between the management of the accident and the concept of engineering thinking in emergency situations. Some of the information it contains is new, and can be classified into three categories: factual, representational and technical.

Institutional reports tell the story of Fukushima Dai Ichi a posteriori. For the sake of completeness, they provide an exhaustive description of all phenomena, notably technical. This approach encourages the authors to relate as facts certain elements that can only have been deduced through simulation, notably the chronology of events established by TEPCO. Certain phenomena were presumed to have happened only after the event, for example that a high concentration of hydrogen was the reason for the explosion of the reactor buildings. Furthermore, the director does not know or does not remember certain facts and details that the investigators tell him. This point is important, in particular to understand the uncertainty that reigned at the Fukushima site after the tsunami hit. It means that decisions must have been taken in the absence of knowledge about certain reactor parameters. Furthermore, the 
emergency response centre had to coordinate multiple tasks simultaneously, which cannot be effectively represented by a classic schema where events follow each other in chronological succession. The decisions and the actions that were taken, with a notable lack of resources, depended on one another. Many important factors came into play, including slow progress in completing tasks, the impact of events on the viability of the site, lessons learned from interventions at other plants, and the mobilization of resources for other activities.

From a representational point of view, some reports (e.g. the NAS document), describe one after another the plant's reactors and the evolution of their states. However, Yoshida's testimony shows that the emergency response centre had to manage the entire site, and try to mitigate the degradation of various facilities at the same time. In addition, his account highlights the extreme complexity of managing the nuclear crisis.

Immediately following the earthquake, the workforce assembled in an anti-seismic building and formed an unofficial emergency response centre. They foresaw, based on the tsunami warning, a potential problem in the reactor cooling system. However, it was the loss of electricity following the tsunami that threw the unit into disarray, "We were all so floored that we were speechless. All we could do was remain calm and get on with administrative tasks, this is what we should do if there is a loss of all AC power, the famous Article 10. But, as I told you earlier, while we carried out these administrative tasks, emotionally, we were annihilated." The team found themselves, from that point on, "faced with a catastrophe" (Guarnieri et al., 2015).

In an accident situation, frustration, nervousness and fear translate into emotional tension that in turn, plays a role in decision making and the actions that are taken. The third dimension, which complements the others, relates to actions taken in the field. The director repeatedly emphasizes the difficulty that workers had in carrying out their tasks. This inability to take effective action, coupled with the incomprehension and impatience of TEPCO executives who were not actually at the site, contributed to the extreme situation experienced by workers (Guarnieri et al., 2015).

Attempts to vent reactor 2, which are only mentioned in a few reports, perfectly illustrate the gap between what was happening in the field and at headquarters. TEPCO headquarters repeatedly issued orders to proceed with venting; although teams worked through the night, no workable solution could be found due to lack of suitable resources. Yo- shida states his annoyance with this lack of understanding, which was perceived by the emergency response centre as a failure to acknowledge the work they were doing, and their ongoing efforts. This only served to increase the frustration of teams who could not make the unit respond to their actions. These strong emotions and the role they play in decision making must be taken into account, if we are to have a better understanding of how the accident was managed.

The analysis of Yoshida's testimony therefore helps to incorporate certain factors that are inherent in the concept of extreme situations. In this context, it is particularly important to note: the uncertain situation at the site; the lack of available resources; hierarchical and social pressure; and the feeling of helplessness in the face of the progressive degradation of the facilities.

Missing facts and the reconstruction of events presented in reports means that there is no accurate representation of the complexity and the challenges experienced by the workforce and the emergency response centre. At the same time, it must be noted that the director's testimony of how events unfolded are a subjective account of what happened. The transcript of his testimony does not necessarily correspond to an objective description of the succession of events as they unfolded at the Fukushima site once the tsunami had hit.

\section{THE RELATIONSHIP BETWEEN ENGINEERING THINKING IN EMERGENCY SITUATIONS AND THE MANAGEMENT OF THE ACCIDENT}

This section demonstrates the usefulness of Yoshida's account of events, based on the analysis of an extract of his testimony. It first briefly contextualises the events that are related in the narrative framework of the management of the crisis, and then highlights the similarities between the director's account of events and certain markers of engineering thinking in emergency situations.

\subsection{Contextualisation of the extract}

The selected extract (Guarnieri et al., 2015: 207224) highlights the three categories of information (factual, technical and representational) described in the previous section.

The excerpt is from the morning of the second day of the hearing, 29 July 2011. It follows a series of questions about the state of the emergency cooling 
systems of reactors 2 and 3, in particular, the decision to inject water into the reactors.

The excerpt begins with a question from the investigators about the management of the accident following the explosion of reactor 1 . Several questions relate to planned interventions on reactors 2 and 3 , as the investigators try to understand the decisions that were taken given the record of the reactors' parameters and the chronology of events. Yoshida is faced with a long series of questions about the course of the accident (based on the chronology provided by TEPCO), and he either answers succinctly, or asks for clarification. Some of his responses are longer, especially when he explains the sequence of events and why decisions were taken. He partially corrects some of the facts stated by the investigators with explanations, from an operational or technical point of view, that justify the actions that were carried out.

He also expresses his personal convictions at the time of the accident, and his feelings about what was happening. He refers to the atmosphere in the emergency response centre ("we were very annoyed"), and the interventions from TEPCO headquarters. The excerpt ends with a break, when the investigators suspend the hearing.

The investigators were interested in the period from 12-13 March. On 11 March, the earthquake and the tsunami had hit the east coast of Japan. While the subsequent loss of electricity prevented the normal functioning of many of the safety devices at the reactor, auxiliary cooling systems kicked in. In accordance with Japanese law on nuclear emergencies, the director set up an on-site emergency response centre. The unit is required to notify TEPCO of any changes in the status of the facilities; TEPCO in turn, informs the Japanese government. Shift teams remained in place and continued to carry out interventions on the nuclear units. They reported back any information they considered necessary to the emergency response centre, which coordinated the various teams.

On the morning of 12 March, the building of reactor 1 exploded. At the same time, the emergency response centre discovered that reactor 3's emergency core cooling systems no longer worked. This meant that they had to find a way to inject water in order to lower the temperature and pressure in the vessel. This manoeuvre was intended to prevent fuel rod damage, given their inability to activate the tank's pressure relief valves.

This work was hampered by both the degraded conditions created by the explosion of reactor 1 and their inability to obtain reliable measurements of the state of reactor 3 . The high pressure in reactor 3 prevented the injection of water into fire prevention circuits; consequently the water level began to fall, while the pressure increased. As preparations were put in place for the injection of water through a makeshift circuit, venting of the containment vessel gradually became inevitable. Venting is the deliberate and controlled release of radioactive steam from the containment vessel of a nuclear reactor; it aims to lower its pressure and temperature and is usually accomplished by opening motor or air operated valves. While the order to begin the manoeuvre was finally issued on the night of 12-13 March, teams in the field were unable to open any valves due to a lack of suitable equipment; their problems were compounded by their inability to measure the reactor's various parameters. Finally, water injection began on the morning of 13 March.

During these many and various attempts to both vent and inject water, TEPCO headquarters continued to interfere with the decisions taken by the emergency response centre. They initially criticized workers for their slowness in carrying out the water injection and prohibited them from using sea water in reactor 1. Moreover, they ordered them to stop spraying water on the containment vessel in order to prepare for venting.

This excerpt sheds light on the management of the accident by Fukushima workers. It highlights the conditions they had to work in and makes it possible to identify the characteristics of engineering thinking in emergency situations in action.

\subsection{The markers of engineering thinking in emergency situations}

The value of this extract is that contains several elements that are not fully reflected in the official reports. It highlights the difficulty experienced by teams in managing multiple events with limited human and material resources, in very hostile conditions and an uncertain situation. Furthermore, it demonstrates the progressive divide that developed between workers and the on-site emergency response centre on the one hand, and TEPCO headquarters on the other.

In such circumstances, individuals find themselves in what can be called an 'extreme' situation that affects decision-making processes and actions (Travadel and Guarnieri, 2015). In such a situation, the actions that are taken fail to "regain control of the production unit, [and] are viewed by society as being responsible for an imminent danger with irrevocable consequences" (Ibid.). 
At the hearing, Yoshida challenges some of the figures put forward by the investigators. He states that certain data could never have been collected and that it must have been deduced at a later date, or that he does not remember. For example, regarding the pressure in reactor 3 , Yoshida states that it was not measured. No-one on the site knew what it was at the time of the accident. It was therefore added at a later date. Whether this data was available or not biases the reading of events, as the inability to access certain data played a fundamental role in the management of the accident, "I would like you to keep in mind the possibility that while we were unable to observe the data; it was possible, later, to insert figures that came from somewhere else. In fact, when we checked the instruments in the emergency response centre, most of the time there were no numbers, collecting data was impossible." (Guarnieri et al., 2015).

In this statement, Yoshida tries to correct the representation that the investigators may have had of how events unfolded. The chronology provided by TEPCO was established a posteriori. Figures that "came from somewhere else" (and were not collected locally) totally distort the sequence of events. The director's description of being "unable to observe the data", saying that "collecting data was impossible" demonstrates their lack of anything that would them to understand the actual state of the plant.

This lack of data highlights the uncertainty of the situation. At times teams had to enter the units with no knowledge at all of their state, "The thing is that we had to manoeuvre without being able to see anything. None of the parameters that we would normally monitor were available. So, when you ask if the venting was successful, I can only say that I do not know. If you need a simple answer, I would say I do not know. If I look at the circumstantial evidence, I would say that it seemed that it was done at one time or another. I can't be any surer. So when people talk as if it was venting under normal conditions in units that were working perfectly, that annoys me as well" (Ibid., 221).

Yoshida once again emphasizes the inaccuracy of the representation created by the chronological timeline, which provides a version of events that is very different to the situation actually experienced by workers. TEPCO, which wanted to establish an exhaustive chronology, provided inaccurate data that led to inaccurate conclusions, such as that venting operations ran smoothly. However, Yoshida insists that understanding his representation of the accident, including the visibility of actors, offers a contextual overview of the decisions that were taken. The diffi- culty in carrying out certain tasks and the frustration of workers are put forward as other key elements in the management of the crisis.

In addition to the very hostile working conditions, a lack of personnel and suitable equipment hampered the work. Furthermore, teams had to perform several tasks simultaneously. The extract highlights the distance that separated the on-site teams and TEPCO headquarters at the representational level. It is seen in the injunctions that are handed down to the emergency response centre by TEPCO, which reinforce the divide between them, "You have three nuclear units that are falling apart, right before your eyes, you're doing the impossible with the few staff you have, and they dare to say that we are too slow? I cannot forgive those people." (Ibid.).

In this quote, Yoshida reminds us of the difficulty of managing the situation with such limited resources. TEPCO's criticism of the slow pace of operations horrified him, and he found it unforgivable. The words reveal the divide between TEPCO and the staff at Fukushima. In general, Yoshida's testimony demonstrates his loyalty to his workforce, to the difficulty that all experienced; the sacrifice of some and the suffering of others. At the same time, he refuses to accept the accusations levelled at them by people who were remote from any immediate danger and the tensions generated by the unfolding events. "Those people" did not understand the challenges of managing the accident and seemed to consider the workforce as either the guilty party, or incompetent.

Teams on the ground had to simultaneously find alternatives to conventional systems, and repair damaged resources (such as the various water supply and storage systems). Workers sought alternative solutions. An important example is the use of car batteries to provide power to instrumentation. As there was no electricity, batteries or generators, workers came up with the idea of using the batteries from their own cars. This initiative was taken despite the state of the roads, the lack of lighting, the risk of seismic shock, the lack of staff and time. Furthermore, the batteries then had to be delivered to the control room to be connected.

\section{CONCLUSION}

This analysis illustrates the value of looking in detail at the testimony of a principal player in the management of the accident. Yoshida's account of events provides valuable material for understanding the management of the post-tsunami situation at $\mathrm{Fu}-$ 
kushima Dai Ichi. His testimony helps to fill in gaps and correct factual inaccuracies present in investigation reports. Finally, it provides an opportunity to identify several markers of extreme situations and indicators of engineering thinking in emergency situations in action.

Further work could use speech or textual analysis tools to look in more detail at the testimony and expand our knowledge of Yoshida's representation of the accident. Specific themes could be selected (such as his relationship with time, or his memory of events) that would improve our understanding of the mechanisms that come into play in such a situation. Their impact on decision making, actions, and engineering organizations, could therefore be identified.

\section{REFERENCES}

ADAM, J.M., 1996, Le récit, P.U.F. “Que sais-je ?”, Paris.

BERNARD, M.C. 2014, La "présentation de soi": cadre pour aborder l'analyse de récits de vie, ¿Interrogations? Revue pluridisciplinaire de sciences humaines et sociales, 17.

BOURDIEU P., 1986, L'illusion biographique. Actes de la recherche en sciences sociales, 62-63: 69-72.

BRUN P, 2003, Le récit de vie dans les sciences sociales, Quart Monde.

BURRICK D., 2010, Une épistémologie du récit de vie, Recherches Qualitatives, Hors-Série (8): 736.

CHAXEL S., FIORELLI C., MOITY-MAÏZI P., 2014, Les récits de vie : outils pour la compréhension et catalyseurs pour l'action, ¿Interrogations? Revue pluridisciplinaire de sciences humaines et sociales, 17.

GUARNIERI F. and TRAVADEL S., 2014, Engineering thinking in emergency situations: A new nuclear safety concept, Bulletin of Atomic Scientists, 70 (6): 79-86.

GUARNIERI F., TRAVADEL S., MARTIN C., PORTELLI A., AFROUSS A., 2015, L'accident de Fukushima Dai Ichi : le récit du directeur de la centrale, volume 1, L'anéantissement, Paris: Presses des Mines, Paris.

ICANPS (Investigation Committee on the Accident at the Fukushima Nuclear Power Stations of Tokyo Electric Power Company), 2012, Final Report.

NOSSIK S., 2011, Les récits de vie comme corpus sociolinguistique : une approche discursive et interactionnelle, Corpus 10: 119-135.
NEA (Nuclear Energy Agency), 2013, The Fukushima-Dai Ichi Nuclear Power Plant Accident OECD/NEA Nuclear Safety, Response and Lessons learnt, NEA No 7161.

NAS (National Academy of Science), 2014, Lessons Learned from the Fukushima Nuclear Accident for Improving Safety of U.S. Nuclear Plants, The National Academies Press. Washington.

NAIIC (The National Diet of Japan), 2012, The Fukushima Nuclear Accident Independent Investigation Commission.

TRAVADEL S. and GUARNIERI F., 2015, L'agir en situation extreme, In GUARNIERI F. (ed.), L'accident de Fukushima Dai Ichi : le récit du directeur de la centrale, volume 1, L'anéantissement. Presses des Mines. Paris.

R. VAN BOESCHOTEN, 2012, Entre témoignages et récits de vie : Quels rapports ? Témoins et témoignages. Figures et objets du Xxe siècle, 1315 December 2012, Paris. 